\title{
Online Lecture Model with WhatsApp Group (WaG) and Google Classroom (GC) Integration
}

Model Perkuliahan Daring dengan Mengintegrasikan WhatsApp Group (WaG) dan Google Classroom (GC)

\begin{tabular}{l}
\hline Author \\
\hline Maskhur Dwi Saputra \\
Universitas Indraprasta PGRI \\
Kel. Gedong, Kec. Pasar Rebo, \\
Jakarta Timur, 13760 \\
maskhurds.peunindra@gmail.com
\end{tabular}

\section{Duconomics} Sci-meet

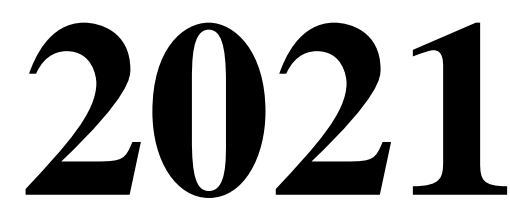

VOLUME 1

JULI

Page

93-106

DOI

10.37010/duconomics.v1.5412

Corresponding Author

maskhurds.peunindra@gmail.com 081328909205
Abstract

The impact of Covid-19 has made educational institutions carry out online learning processes; thus, they must provide innovative

learning media so that students continue to get material

explanations like in face-to-face learning. This study aims to design and evaluate an online lecture model by integrating $W a G$ and GC. Using descriptive method, this study involves Economic

Education students at Universitas Indraprasta PGRI for the academic year 2020/2021 who received 276 scientific writing courses. This study consists of (1) designing WaG and GC media, (2) providing the lecture material on the learning media,

(3) implementing the media in lecture activities, and (4) evaluating the effectiveness of the media. The questionnaire shows that learning media by integrating WaG and $G C$ is effective to be applied. This is indicated by the percentage of students who strongly agree (54\%), agree (32.5\%), quite agree $(11.2 \%)$, disagree $(1.6 \%)$, and strongly disagree $(0.7 \%)$. The evaluation includes ease of access, affordability, understanding

of the material, two-way communication, media updates, and ease of using technology.

Keywords

Online Learning, WhatsApp, Google Classroom.

Abstrak

Dampak covid-19 mendorong lembaga pendidikan melaksanakan proses pembelajaran secara daring, oleh karena itu lembaga pendidikan harus menyediakan media pembelajaran yang inovasi agar peserta didik tetap mendapatkan penjelasan materi seperti pembelajaran tatap muka. Tujuan dari penelitian ini yaitu untuk merancang dan mengevaluasi model perkuliahan daring dengan mengintegrasikan $\mathrm{WaG}$ dan GC. Penelitian ini menggunakan metode deskriptif dengan melibatkan mahasiswa

Pendidikan Ekonomi Universitas Indraprasta PGRI tahun akademik 2020/2021 yang mendapatkan mata kuliah penulisan ilmiah sebanyak 276 mahasiswa. Proses penelitian terdiri dari (1) merancang media WaG dan GC; (2) mengisi materi perkuliahan pada media pembelajaran; (3)

mengimplementasikan media pembelajaran pada kegiatan perkuliahan; (4) evaluasi keefektivan media pembelajaran. Hasil pengisian kuesioner menunjukkan media pembelajaran dengan mengintegrasikan antara WaG dan GC efektif untuk diterapkan.

Hal ini ditunjukkan dengan persentase mahasiswa yang menyatakan sangat setuju sebesar $54 \%$, setuju $32,5 \%$, cukup setuju $11,2 \%$, tidak setuju $1,6 \%$, dan sangat tidak setuju $0,7 \%$. Evaluasi tersebut meliputi kemudahan akses, keterjangkauan biaya, pemahaman materi, komunikasi dua arah, keterbaruan media, kemudahan dalam menggunakan teknologi.

Kata kunci

Pembelajaran daring, WhatsApp, Google Classroom 


\section{$412 \begin{aligned} & \text { Duconomics Sci-meet (Education and Economics Science Meet) } 2021 \\ & \text { https://s.id/Duconomics } \\ & \text { Merdeka Belajar dan Tantangan Ekonomi dalam Menyongsong Era Society } 5.0\end{aligned}$}

\section{PENDAHULUAN}

Wabah covid-19 di Indonesia sudah berlangsung selama satu tahun, akan tetapi penyebarannya masih mengalami fluktuasi. Kondisi ini membuat pemerintah belum berani secara tegas untuk membuka lembaga pendidikan. Berdasarkan hal tersebut proses pembelajaran dari tingkat PAUD hingga perguruan tinggi masih dilaksanakan secara daring. Namun, Menteri Pendidikan dan Kebudayaan sudah memperbolehkan daerah zona hijau dan kuning melaksanakan pembelajaran tatap muka dengan protokol kesehatan yang ketat, akan tetapi keputusan untuk membuka lembaga pendidikan diserahkan kepada pemerintah daerah, sekolah, dan orang tua siswa (Novelino, 2020).

Kebijakan untuk tetap melakukan pembelajaran daring tetap dijalankan oleh lembaga pendidikan di wilayah Jakarta. Hal ini dikarenakan wilayah Jakarta penyebaran covid-19 masih cukup tinggi. Salah satu lembaga pendidikan yang masih menerapkan pembelajaran daring yaitu Universitas Indraprasta PGRI (Unindra), hal ini disampaikan oleh rektor melalui surat edaran nomor 10/R/UNINDRA/III/2020 tanggal 27 Maret 2020. Pada saat ini fasilitas pembelajaran daring sudah disediakan oleh pihak Unindra melalui SIKA (Sistem Informasi Kemahasiswaan dan Akademi) yang terintegrasi dengan LMS (Learning Management System). Namun, fasilitas tersebut kadang masing sering mengalami error jika digunakan secara bersamaan.

Kendala yang terjadi terhadap fasilitas pembelajaran daring tersebut (SIKA dan LMS) membuat tenaga pengajar/dosen harus mampu secara cepat, kreatif, dan inovatif mencari solusi alternatif untuk menyampaikan materi kepada mahasiswa. Hal ini dikarenakan agar waktu yang dibutuhkan mahasiswa untuk menempuh pendidikan dapat selesai tepat waktu, sehingga mahasiswa memiliki kompetensi untuk digunakan terjun ke masyarakat. Tenaga pengajar/dosen dapat memanfaatkan fasilitas pembelajaran online yang dapat dijangkau, seperti Zoom Meeting, WhatsApp, Telegram, Instagram, Youtube, Facebook, Google Meeting, Google Classroom dan lain sebagainya.

Namun, pemilihan media pembelajaran tidak begitu saja untuk dipilih. Tenaga pengajar/dosen tersebut harus memperhatikan kriteria media yang akan digunakan. Menurut Susilana dan Riyana (2009) kriteria media yang baik harus memenuhi unsur ACTION yaitu Access (media mudah diakses), Cost (biaya yang dapat dijangkau), Technology (media tersebut didukung dengan teknologi yang ada), Interactivity (media dapat digunakan untuk berinteraksi), Organization (media yang digunakan mendapat dukungan dari instansi), Novelty (media yang digunakan memiliki keterbaruan).

Berdasarkan permasalahan dan pertimbangan kriteria pemilihan media tersebut, maka proses perkuliahan dapat dilakukan dengan mengintegrasikan aplikasi WhatsApp Group (WaG) dan Google Classroom (GC). Pemilihan media tersebut dilakukan karena semua mahasiswa menggunakan aplikasi WhatsApp, sedangkan untuk GC penggunaannya mudah yaitu tinggal masuk dengan akun $g$-mail dimana mayoritas mahasiswa memiliki akun ini. Jadi penelitian ini berusaha mencari solusi dari pemasalahan yang ada yaitu merancang model perkuliahan dengan mengintegrasikan aplikasi $\mathrm{WaG}$ dan GC.

Aplikasi WhatsApp banyak digunakan oleh kalangan masyarakat khususnya mahasiswa, hal ini dikarenakan aplikasi tersebut hampir dapat dioperasikan di semua perangkat smartphone (Hanisi, Risdiany, Utami, \& Sulisworo, 2018). Aplikasi tersebut menawarkan berbagai fitur 
yang dapat mempermudah seseorang melakukan komunikasi. Fitur yang tersedia berupa layanan chatting seperti SMS pada umumnya, kirim pesan berupa video, foto, dan suara, serta layanan video call secara langsung dengan terkoneksi melalui jaringan internet (Oriji \& Anikpo, 2019).

Selain itu Rahaded, Puspitasari, \& Hidayati (2020) menyatakan bahwa aplikasi WhatsApp ini juga memiliki fitur untuk membuat group, sehingga pesan dapat tersampaikan dalam waktu yang bersamaan. Berbagai fitur yang disediakan oleh aplikasi WhatsApp tersebut, membuat aplikasi ini dapat digunakan untuk proses pembelajaran/perkuliahan (Cetinkaya, 2017). Fitur WaG ini berisikan anggota setiap peserta didik dan pengajar, sehingga instruksi yang diberikan oleh pengajar dapat dibaca oleh semua peserta didik dalam waktu yang bersamaan.

Namun pembelajaran melalui $\mathrm{WaG}$ tersebut memiliki sisi yang tidak efektif, seperti yang diungkapkan oleh Cetinkaya (2017) ketika peserta didik sedang belajar menggunakan WaG kadangkala ada pesan masuk dari grup lain atau orang lain, hal ini dapat mengganggu konsentrasi peserta didik. Selain itu banyak dari peserta didik yang mengirim pesan di grup tidak sesuai dengan topik pelajaran dan hal tersebut di kirim diluar jam pelajaran. Lebih lanjut Baishya \& Maheshwari (2020) untuk menghindari pesan yang tidak sesuai dengan topik, anggota grup dapat mematikan pemberitahuan suara/mute akan tetapi mereka dapat ketinggalan informasi yang disampaikan pengajar.

Berdasarkan ketidakefektifan melalui $\mathrm{WaG}$ tersebut, maka penelitian ini mengintegrasikan proses pembelajaran dengan GC. Menurut Albashtawi dan Al Batainch (2020) bahwa GC merupakan suatu platform pembelajaran online yang inovatif. Hal ini diperjelas oleh Keeler dan Miller (2015) bahwa platform online tersebut dapat dimanfaatkan oleh guru untuk membuat kelas maya, sehingga peserta didik mengakses materi dari kelas maya tersebut dengan cara menerima undangan dari guru melalui e-mail. Guru dapat mengisi dengan konten materi pelajaran, tugas, absensi dan dokumen lain yang dibutuhkan peserta didik.

Berdasarkan hal yang terdapat dari kedua media WaG dan GC tersebut, maka perkuliahan yang dilakukan yaitu mengintegrasikan kedua media tersebut. Aplikasi WaG digunakan untuk membentuk grup kelas, sedangkan GC digunakan sebagai tempat untuk memberikan materi perkuliahan, absen, tugas, kuis, UTS, dan UAS. Jadi artikel penelitian ini bertujuan untuk mendeskripsikan rancangan model perkuliahan daring dengan mengintegrasikan WaG dan GC.

\section{METODE}

Penelitian pada artikel ini termasuk dalam jenis penelitian deskriptif yaitu menjelaskan rancangan model perkuliahan dengan mengintegrasikan WaG dan GC. Penelitian ini dilakukan pada semester genap tahun ajaran 2020/2021 yang melibatkan 276 mahasiswa Program Studi Pendidikan Ekonomi Universitas Indraprasta PGRI pada mata kuliah Penulisan Ilmiah. Penelitian ini dilakukan dengan beberapa tahap yaitu (1) perancangan; (2) pengisian materi; (3) pengimplementasian; (4) evaluasi. Pada tahap evaluasi dilakukan penyebaran instrumen berupa kuesioner untuk melihat tingkat efektivitas media pembelajaran.

\section{HASIL DAN PEMBAHASAN}


Hasil

Penelitian ini memiliki beberapa langkah dalam pengimplementasiannya. Langkah pertama dalam penelitian ini yaitu merancang media pembelajaran berupa pembentukan $\mathrm{WaG}$ dan membuat kelas di GC. Pembuatan WaG dilakukan oleh dosen yang bersangkutan, kemudian dosen memberikan link $\mathrm{WaG}$ kepada masing-masing ketua kelas untuk disebarluaskan ke mahasiswa yang lainnya. Setelah itu, pembuatan kelas di GC yang dilakukan oleh dosen yang bersangkutan. Selanjutnya kode dan link GC akan disematkan pada deskripsi box $\mathrm{WaG}$, sehingga mahasiswa yang ada di $\mathrm{WaG}$ tersebut langsung dapat mengakses kelas GC.

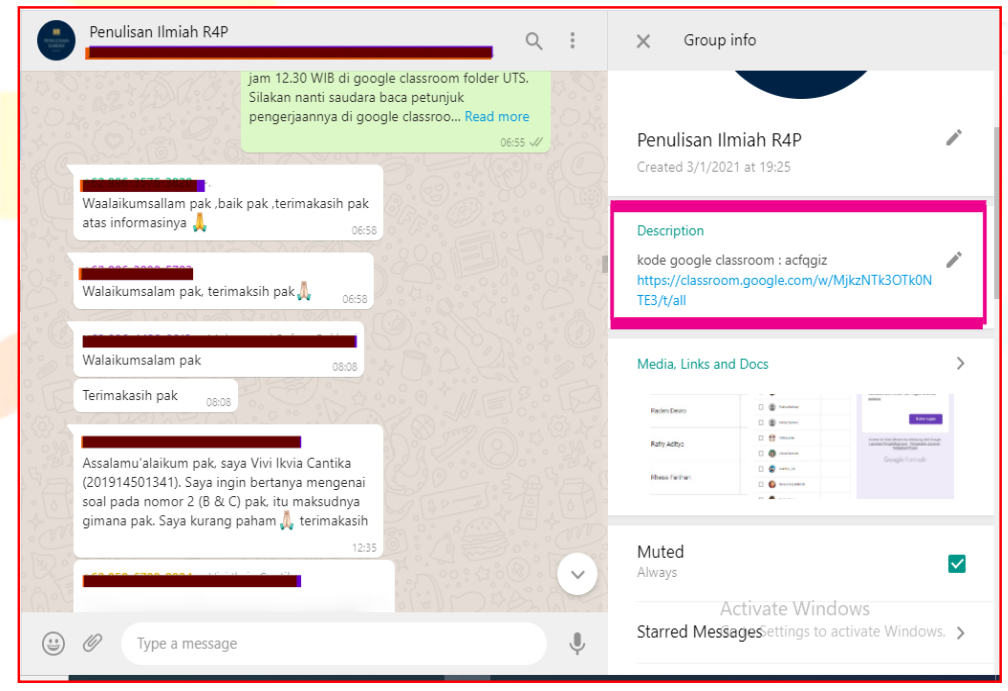

Sumber: Screenshot WhatsApp Group (2021)

Gambar 1. Tampilan Kode dan Link GC pada Deskripsi Box WaG

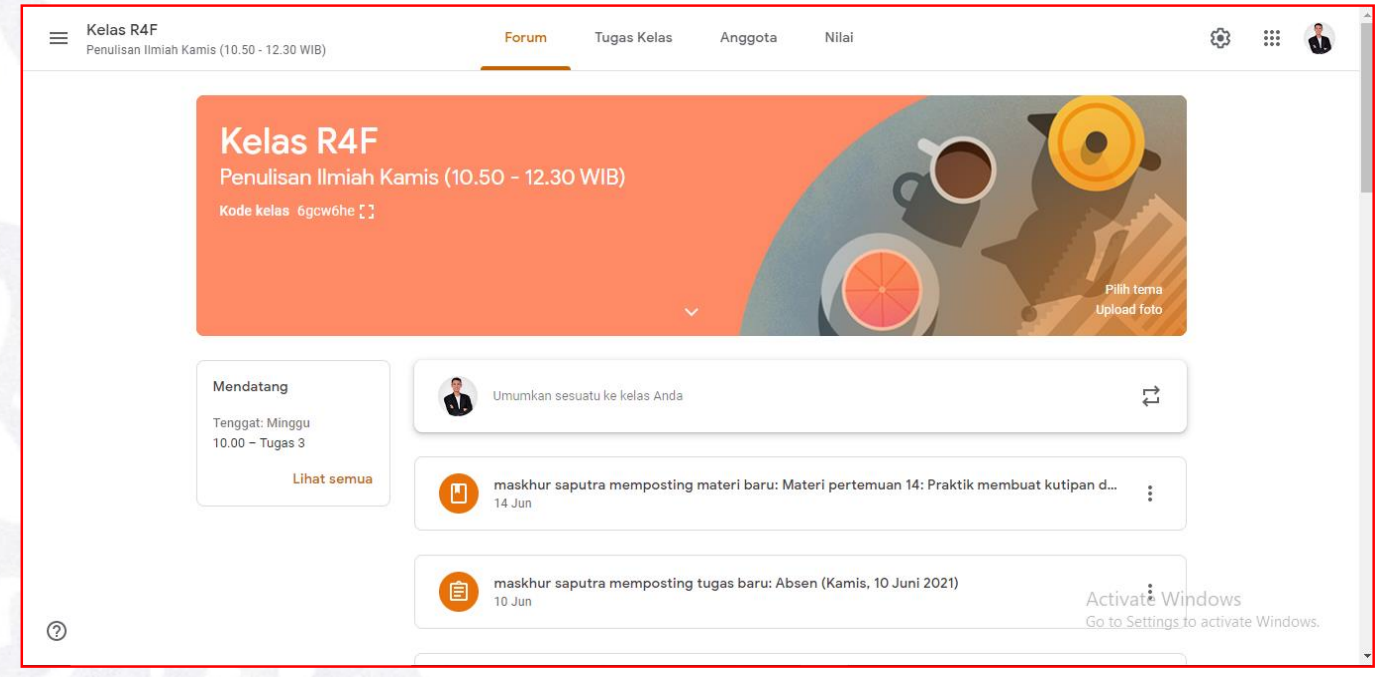

Sumber: Screenshot Kelas GC (2021)

Gambar 2. Tampilan kelas GC

Pada langkah kedua penelitian ini yaitu melakukan pengisian materi di GC. Materi disampaikan dengan beberapa cara, meliputi:

1. Membuat powerpoint kemudian direkam menggunakan aplikasi Camtasia Studio-8. Hasil perekaman di-upload pada channel youtube dengan link sebagai berikut https://www.youtube.com/channel/UCZ5-W1osSh6y4YWU-4M9zUA. 




Sumber: Screenshot Camtasia Studio-8 (2021)

Gambar 2. Tampilan Menu Camtasia Studi-8

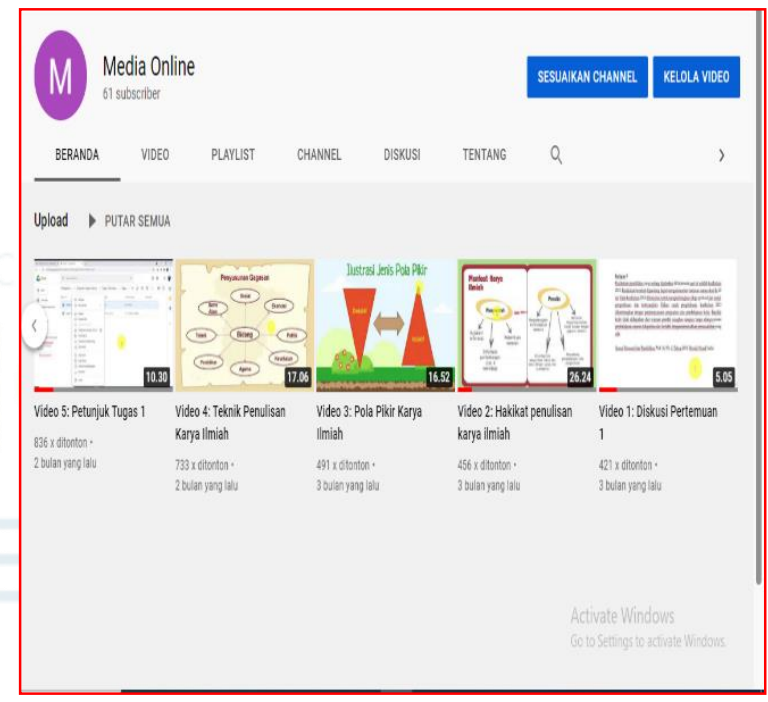

Sumber: Screenshot Youtube (2021)

Gambar 3. Kumpulan Video di Youtube

2. Membuat handout dengan flip pdf corporate, hal ini dilakukan agar mahasiswa juga terbiasa membaca dan tidak hanya melihat materi melalui audio-visual saja. Hasil handout dapat dilihat pada link berikut ini https://gracious-almeida-7fed91.netlify.app/.



Sumber: Screenshot Handout (2021)

Gambar 4. Tampilan Handout Bahan Ajar

3. Membuat poster dari powerpoint, kemudian disimpan dalam bentuk jpg. Berikut contoh materi yang dibuat dalam bentuk jpg: 


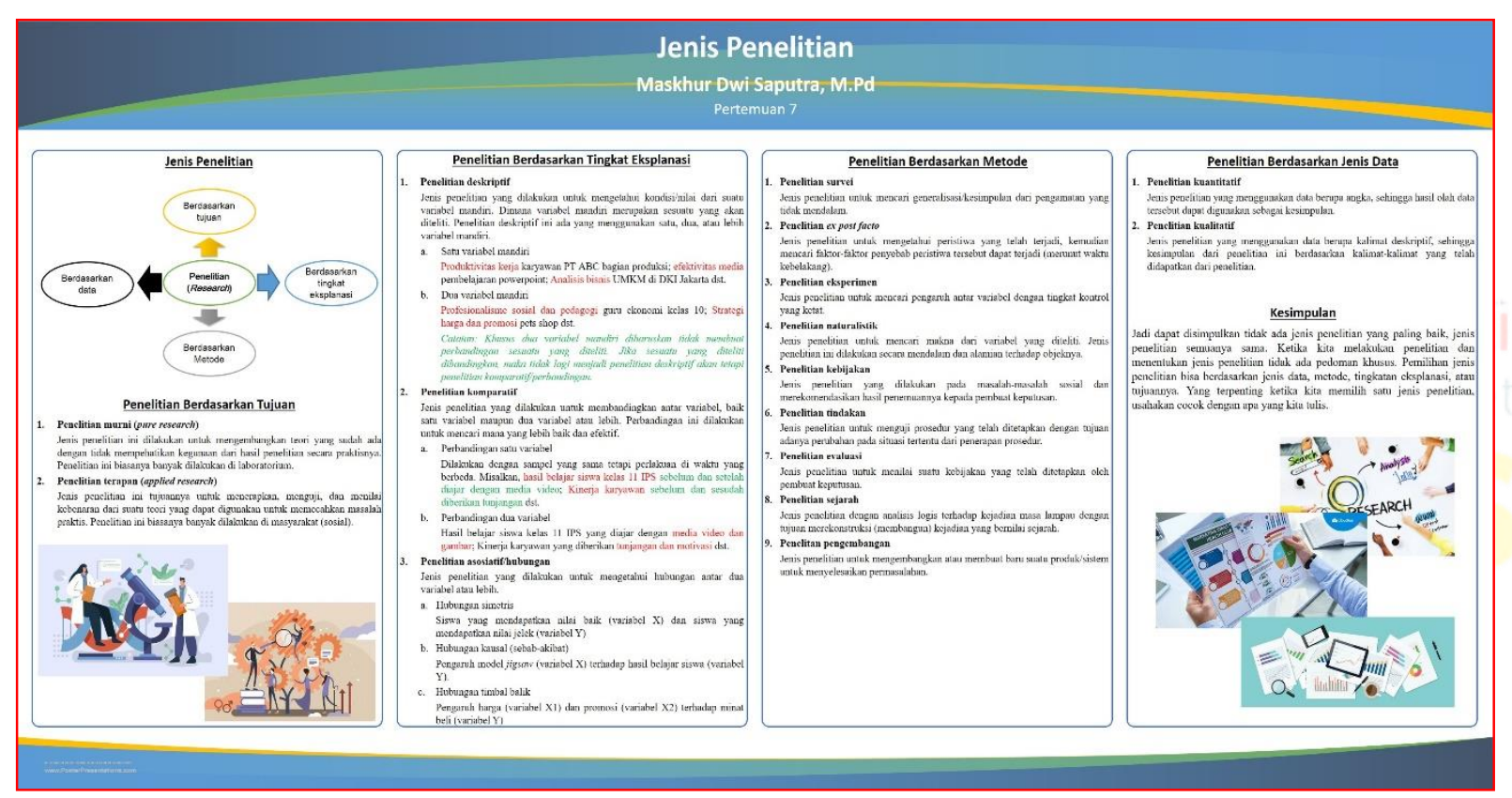

Sumber: Screenshot Gambar Poster (2021)

Gambar 5. Tampilan Poster Bahan Ajar

4. Setelah membuat materi kemudian mengisi materi pada kelas GC. Pengisian materi pada kelas GC ini dilakukan setiap pertemuan yang dapat dilihat pada topik "Materi." Selain itu, pada kelas GC juga dilengkapi topik lain seperti absen, perkenalan, kuis, tugas, UTS dan UAS. Berikut contoh dari komponen pada kelas GC yang ada di menu "Tugas Kelas":

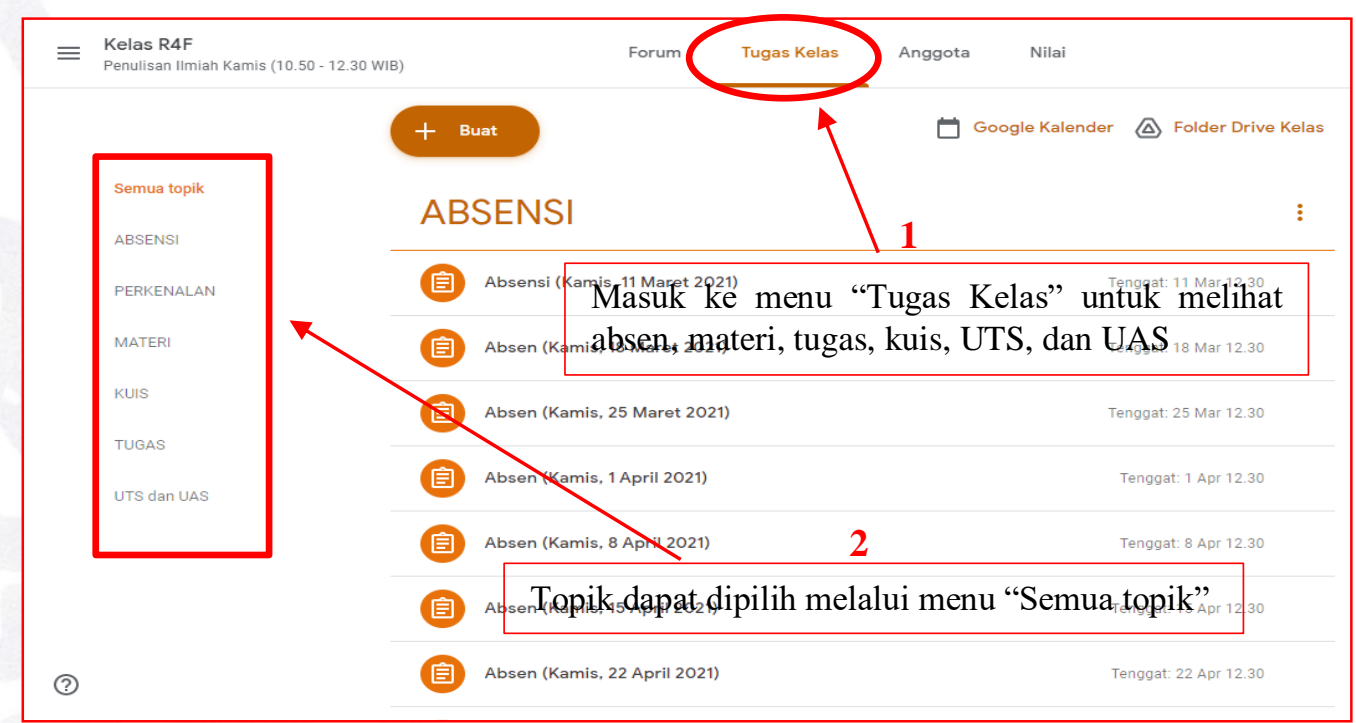

Sumber: Screenshot Kelas GC (2021)

Gambar 6. Tampilan Tugas Kelas GC

Tahap penelitian selanjutnya langkah ketiga yaitu mengimplementasikan media yang sudah dibuat kepada mahasiswa. Tahap implementasi ini dilakukan sesuai jadwal setiap kelas dengan prosedur yang sama. Berikut prosedur implementasi perkuliahan daring dengan $\mathrm{WaG}$ dan GC: 
Duconomics Sci-meet Vol. 1

Juli, 2021

1. Dosen membuka kelas pada WaG meliputi mengucapakan salam, menanyakan kabar, memberitahu materi pertemuan saat itu, mengarahkan untuk membuka kelas pada GC, dan mengingatkan untuk absen.



Sumber: Screenshot WhatsApp Group (2021)

Gambar 7. Tampilan Pembukaan Perkuliahan di kelas GC

2. Berdasarkan instruksi dari dosen dari $\mathrm{WaG}$, selanjutnya mahasiswa menuju kelas GC untuk melakukan absen, mempelajari materi, dan mengikuti instruksi pada pertemuan saat itu.

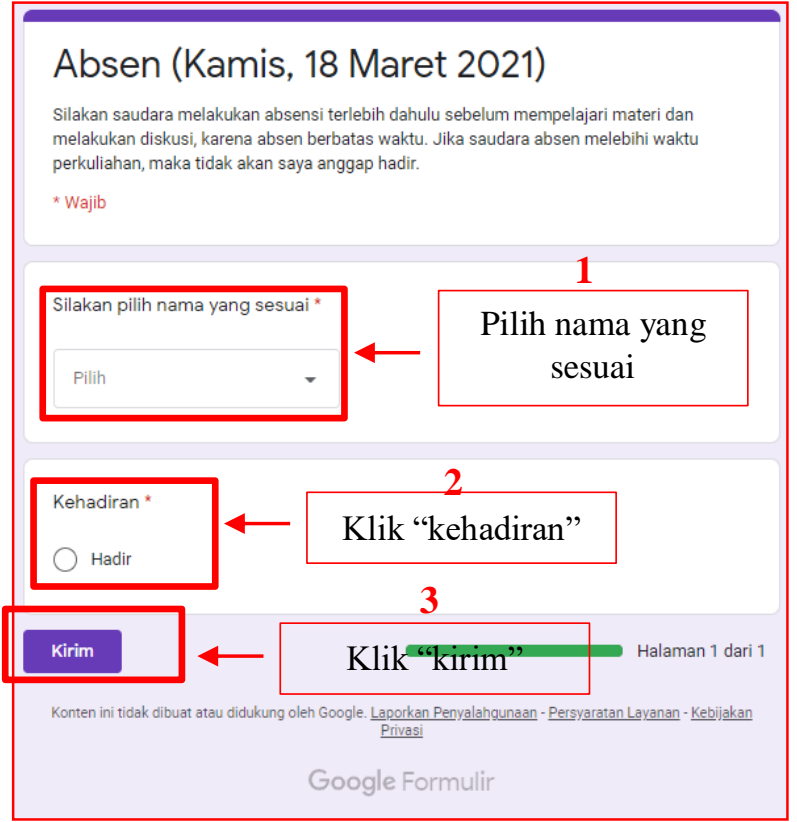

Sumber: Screenshot Kelas GC (2021)

Gambar 8. Tampilan Absen GC



Sumber: Screenshot Kelas GC (2021)

Gambar 9. Tampilan Materi di GC 
3. Setelah mempelajari materi perkuliahan, kemudian mahasiswa melakukan diskusi pada link yang telah disediakan di folder materi perkuliahan pada pertemuan saat itu. Berikut salah satu link yang digunakan mahasiswa untuk berdiskusi https://web.facebook.com/groups/199777598591162.

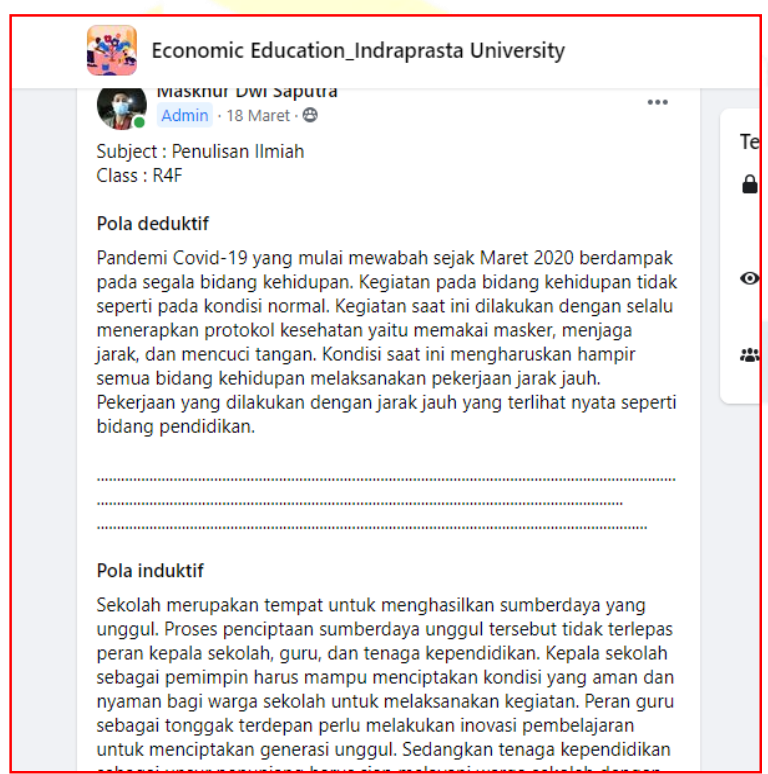

Sumber: Screenshot Grup Diskusi Facebook (2021)

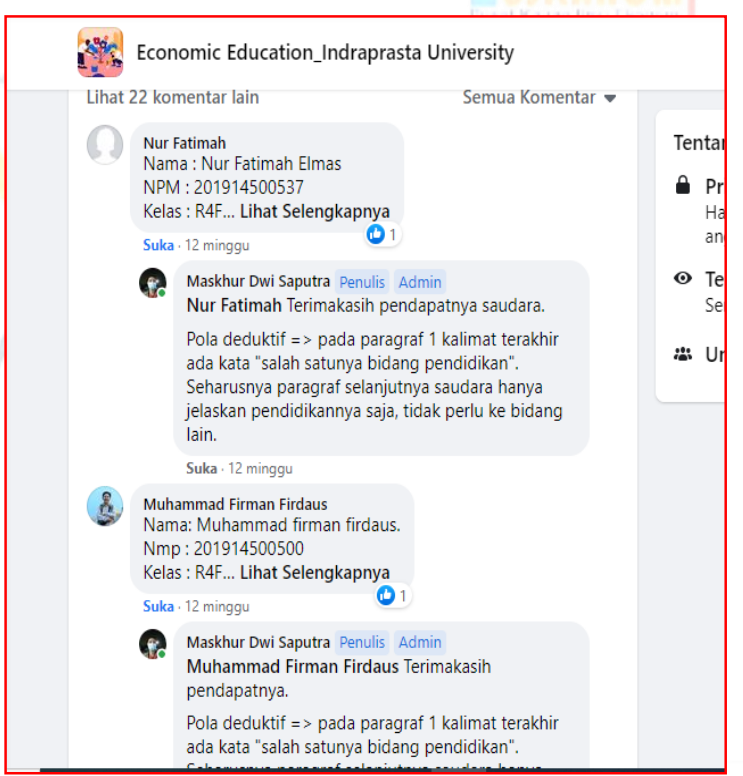

Sumber: Screenshot Grup Diskusi Facebook (2021)

Gambar 11. Tampilan Hasil Diskusi Mahasiswa

4. Selama perkuliahan berlangsung, dosen juga mengecek absensi mahasiswa di GC. Apabila ada mahasiswa yang belum melakukan absen, maka dosen akan mengingatkan melalui WaG. Berikut contoh dosen mengingatkan mahasiswa ketika belum absen:

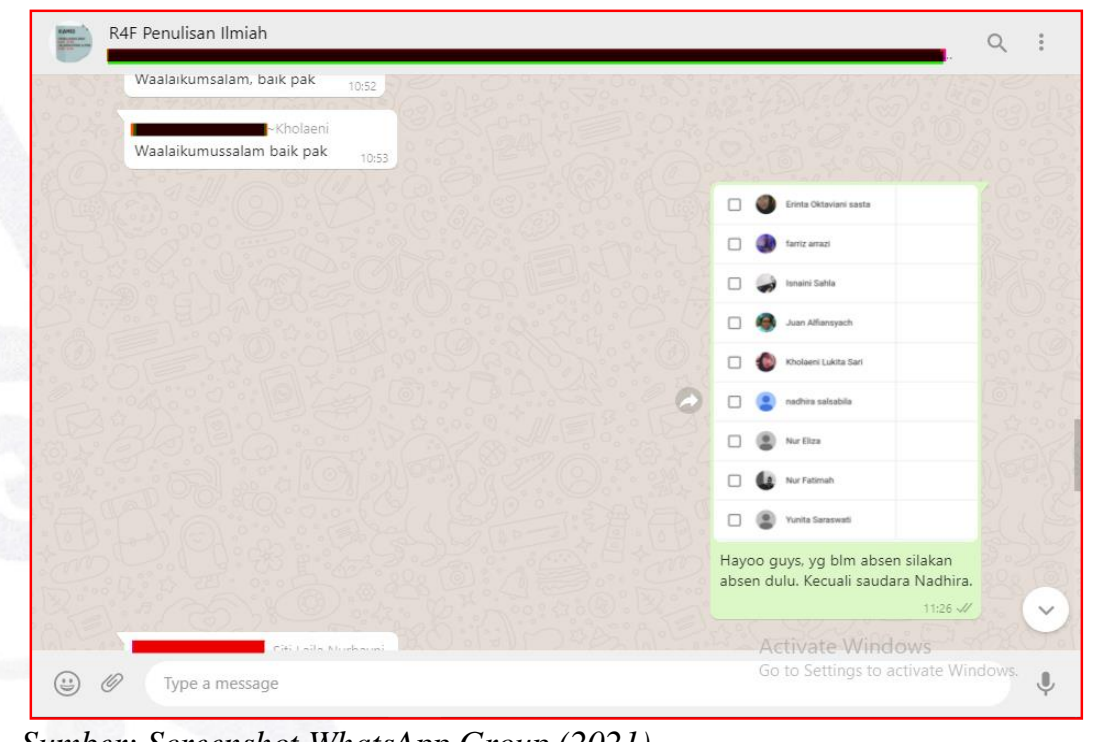

Sumber: Screenshot WhatsApp Group (2021)

Gambar 12. Tampilan Pengingat Absen di WaG 
Duconomics Sci-meet Vol. 1

Juli, 2021

5. Selain mempelajari materi perkuliahan dan diskusi, di kelas GC ini mahasiswa juga dapat mengakses kuis, tugas, dan soal UTS. Hal tersebut dilakukan sesuai pertemuan yang bersangkutan. Berikut contoh folder kuis, tugas, dan soal UTS pada kelas GC:

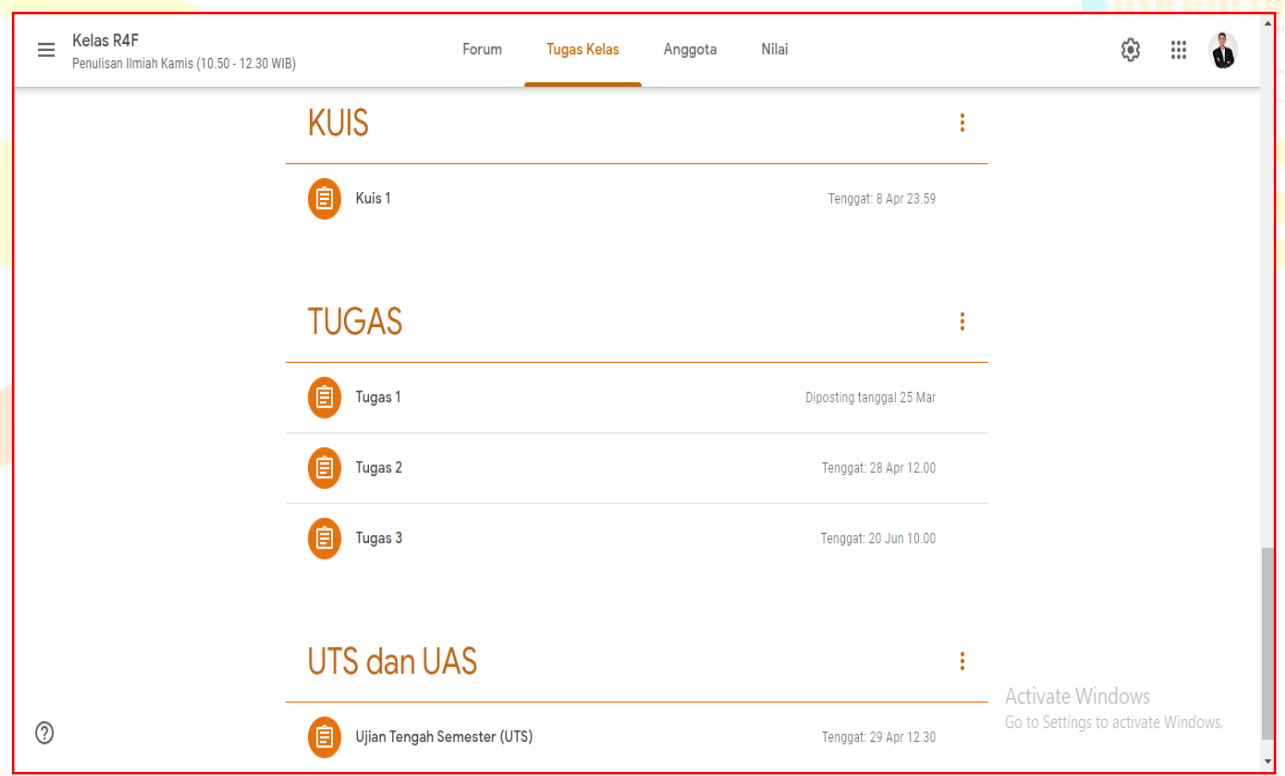

Sumber: Screenshot Kelas GC (2021)

Gambar 13. Tampilan Folder Kuis, Tugas, dan Soal UTS Kelas GC

6. Pada akhir jam perkuliahan, dosen memberikan nilai tentang aktivitas yang dilakukan mahasiswa pada pertemuan saat itu. Rekapitulasi nilai dilakukan secara terpisah menggunakan file excel.

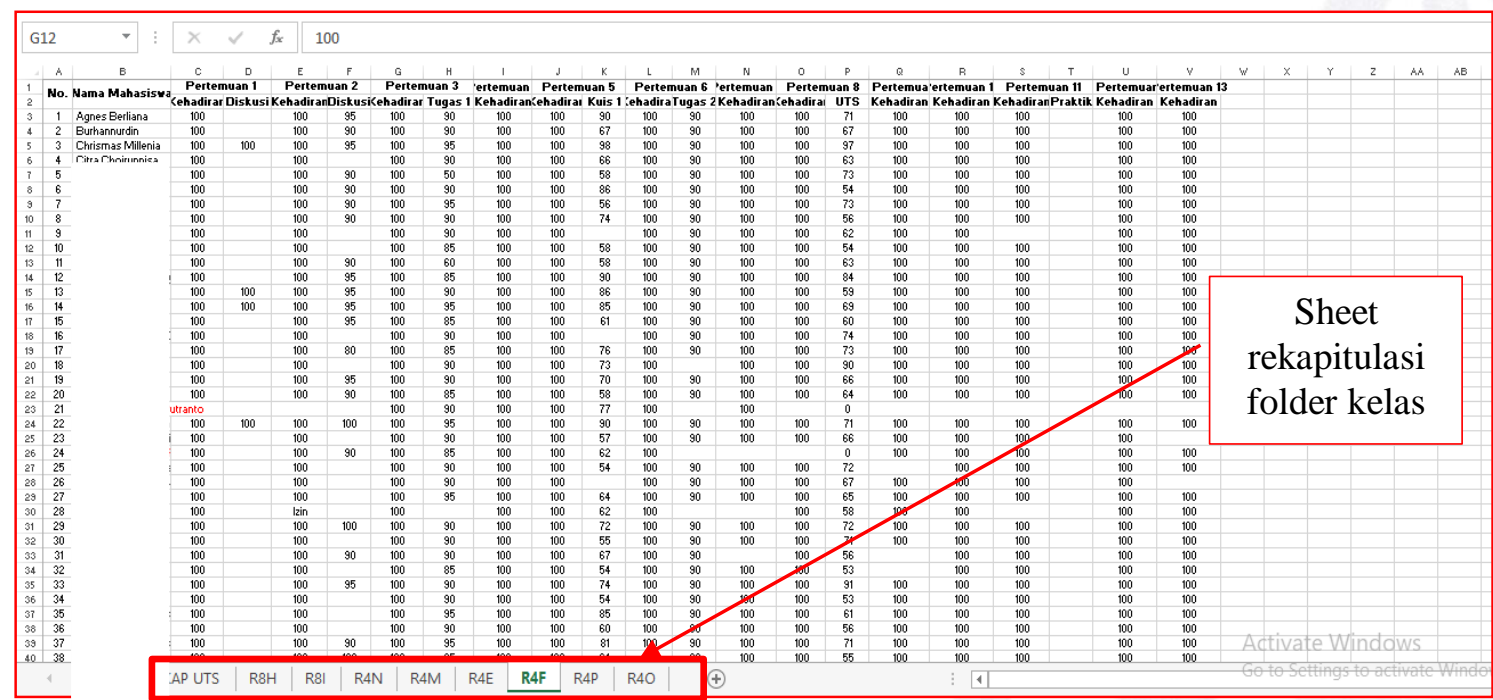

Sumber: Screenshot File Excel (2021)

Gambar 14. Tampilan Rekapitulasi Penilaian Aktivitas Mahasiswa

7. Setelah jam perkuliahan berakhir dosen menutup kegiatan perkuliahan melalui WaG. Penutup memuat tentang pemberitahuan waktu berakhirnya perkuliahan, menyimpulkan materi perkuliaha pada pertemuan saat itu, salam penutup. 


\section{2

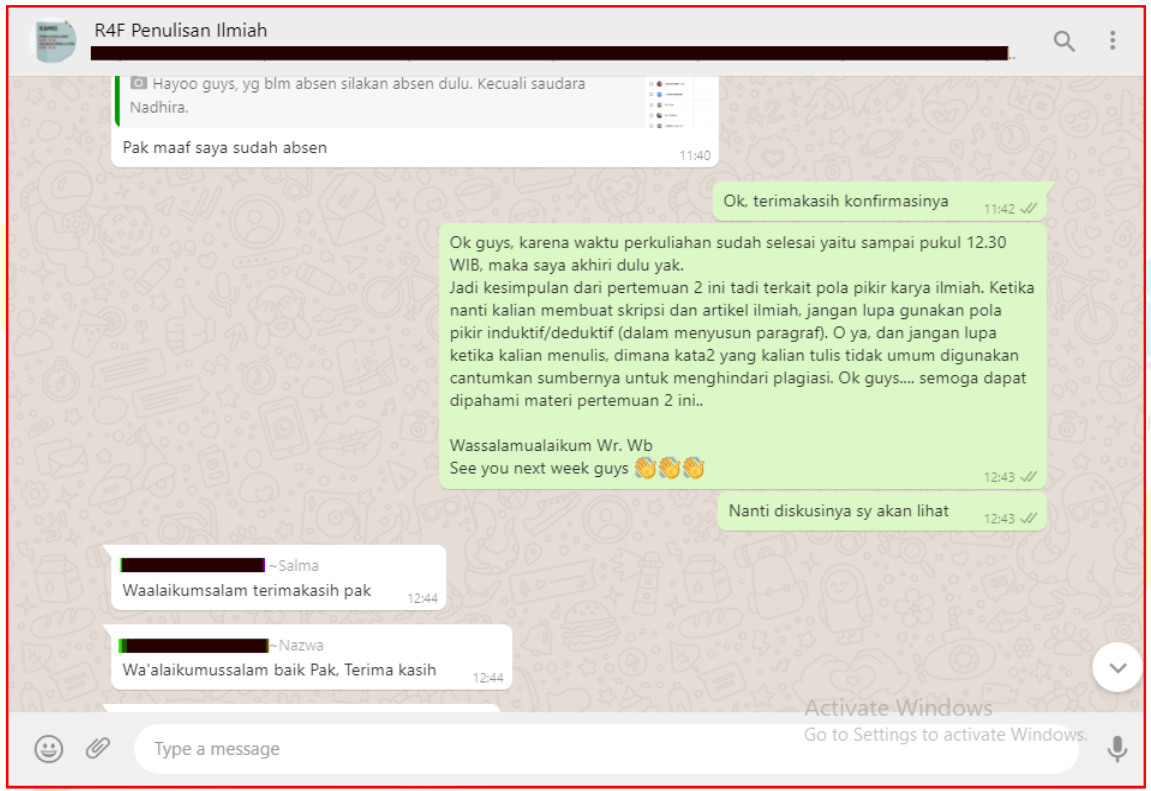

Sumber: Screenshot WhatsApp Group (2021)

Gambar 15. Tampilan Penutupan Perkuliahan di Kelas GC

Langkah keempat dari penelitian ini merupakan evaluasi terhadap proses perkuliahan dengan menggunakan $\mathrm{WaG}$ dan GC. Evaluasi dilakukan dengan memberikan kuesioner kepada mahasiswa untuk memberikan tanggapannya terhadap perkuliahan selama menggunakan $\mathrm{WaG}$ dan GC. Hasil kuesioner dapat dilihat pada tabel di bawah ini:

Tabel 1. Hasil Evaluasi Perkuliahan WaG dan GC

\begin{tabular}{llccccc}
\hline & & \multicolumn{5}{c}{ Persentase Pengukuran } \\
\cline { 3 - 7 } No. & \multicolumn{1}{c}{ Unsur Evaluasi } & $\begin{array}{c}\text { Sangat } \\
\text { Setuju }\end{array}$ & Setuju & $\begin{array}{c}\text { Cukup } \\
\text { Setuju }\end{array}$ & $\begin{array}{c}\text { Tidak } \\
\text { Setuju }\end{array}$ & $\begin{array}{c}\text { Sangat } \\
\text { Tidak } \\
\text { Setuju }\end{array}$ \\
\hline 1 & Kemudahan untuk akses & $70,3 \%$ & $22,5 \%$ & $6,5 \%$ & $0,7 \%$ & $0 \%$ \\
2 & Mudah memahami materi & $39,9 \%$ & $42 \%$ & $17,4 \%$ & $0,7 \%$ & $0 \%$ \\
3 & Biaya terjangkau & $58 \%$ & $26,1 \%$ & $10,9 \%$ & $3,6 \%$ & $1,4 \%$ \\
4 & Mudah menggunakan teknologi & $60,9 \%$ & $30,4 \%$ & $6,5 \%$ & $0,7 \%$ & $1,4 \%$ \\
5 & Komunikasi dua arah & $45,7 \%$ & $39,1 \%$ & $13,8 \%$ & $0,7 \%$ & $0,7 \%$ \\
6 & Keterbaruan media & $49,3 \%$ & $34,8 \%$ & $12,3 \%$ & $2,9 \%$ & $0,7 \%$ \\
\hline & Persentase Keseluruhan & $\mathbf{5 4 , 0 \%}$ & $\mathbf{3 2 , 5 \%}$ & $\mathbf{1 1 , 2 \%}$ & $\mathbf{1 , 6 \%}$ & $\mathbf{0 , 7 \%}$ \\
\hline
\end{tabular}

Sumber: Data Diolah (2021)

Berdasarkan tabel 1 diatas dapat dideskripsikan bahwa dari unsur evaluasi tersebut mahasiswa sangat setuju bahwa media pembelajaran WaG dan GC mudah untuk diakses, hal ini ditunjukkan dengan persentase sebesar 70,3\%. Selain itu, mahasiswa menyatakan setuju jika media pembelajaran tersebut mudah untuk digunakan memahami materi, hal ini ditunjukkan dengan persentase sebesar $42 \%$. Media pembelajaran WaG dan GC memiliki biaya terjangkau untuk mengaksesnya, hal ini ditunjukkan dengan jawaban mahasiswa sangat setuju sebesar $58 \%$.

Selanjutnya teknologi yang dimiliki mahasiswa ternyata dapat digunakan untuk mengakses media pembelajaran tersebut, hal ini ditunjukkan dengan jawaban mahasiswa yang sangat setuju sebesar $60,9 \%$. Media pembelajaran yang digunakan untuk perkuliahan dapat digunakan untuk berkomunikasi dua arah/diskusi dengan dosen/mahasiswa lain, hal ini 
ditunjukkan dengan persentase sangat setuju sebesar $45,7 \%$. Selain itu, media pembelajaran memiliki keterbaruan dengan jawaban mahasiswa sangat setuju sebesar 49,3\%.

Mahasiswa dalam mengakses media pembelajaran WaG dan GC paling banyak menggunakan handphone yaitu sebesar 90,6\%. Selain itu, yang menggunakan laptop/komputer hanya sebesar $8,7 \%$, sedangkan yang menggunakan tablet tidak ada. Mahasiswa juga mengakses media tersebut melalui cara lain, hal ini tunjukkan dengan persentase sebesar $0,7 \%$. Deskripsi tentang teknologi yang digunakan mahasiswa untuk mengakses media pembelajaran tersebut dapat dilihat dari gambar di bawah ini:

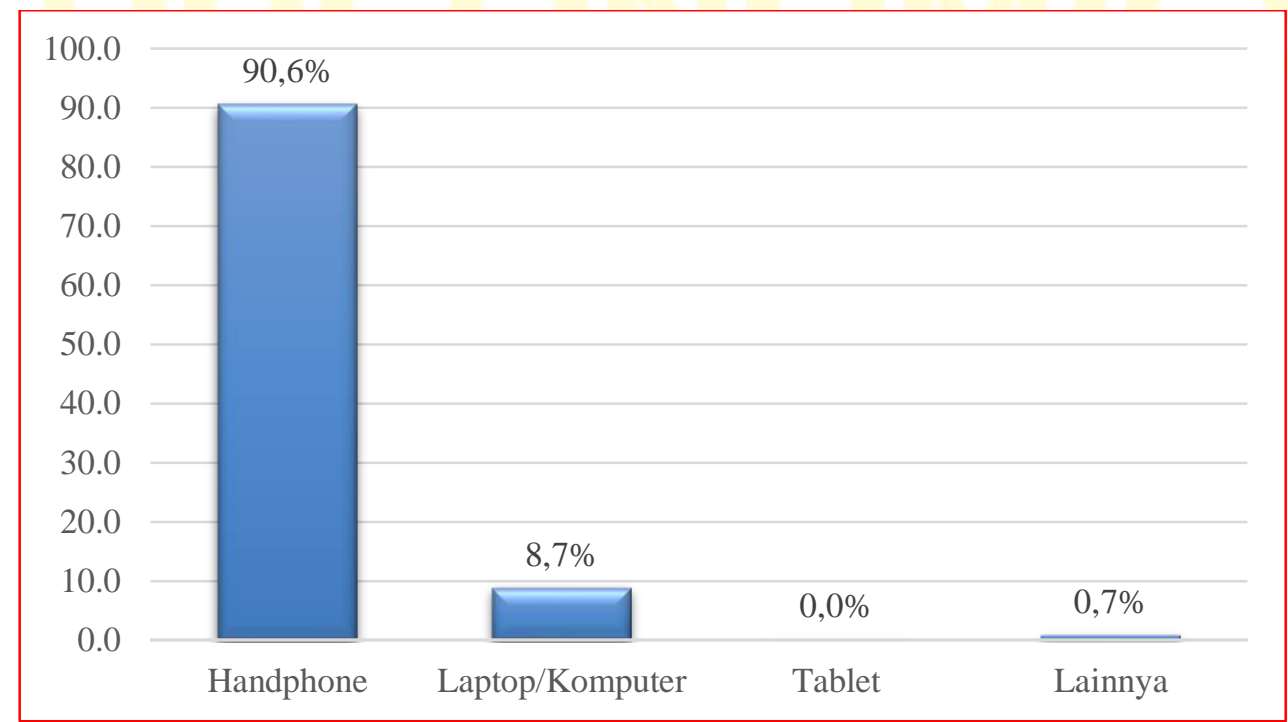

Sumber: Data Diolah (2021)

Gambar 16. Tampilan Histogram Penggunaan Teknologi

\section{Pembahasan}

Penelitian model perkuliahan daring dengan mengintegrasikan WaG dan GC ini efektif digunakan pada proses pembelajaran. Model perkuliahan tersebut di evaluasi dengan mengacu pada unsur kemudahan akses, pemahaman materi oleh mahasiswa, biaya, teknologi yang mendukung, komunikasi dua arah, dan keterbaruan (Susilana \& Riyana, 2009). Evaluasi tersebut dilakukan oleh mahasiswa yang telah mengikuti perkuliahan dengan model WaG dan GC selama tujuh pertemuan.

Kemudahan akses berhubungan dengan ketersediaan media, mudah digunakan, dan dapat dimanfaatkan oleh peserta didik (Susilana \& Riyana, 2009). Model perkuliahan dengan memanfaatkan WaG dan GC ini dilakukan karena mahasiswa Pendidikan Ekonomi Unindra yang berjumlah 276 pada mata kuliah penulisan ilmiah memiliki aplikasi WA dan alamat $g$ mail, sehingga mahasiswa dapat dengan mudah memanfaatkan dan menggunakan media yang tersebut.

Pemanfaatan aplikasi WA menurut Ahmed dan Indurkhya (2020) sudah banyak digunakan oleh peserta didik untuk berkomunikasi melalui handphone, sehingga hal ini dapat dimanfaatkan juga untuk proses pembelajaran. Selain itu menurut Mishra, Gupta, dan Shree (2020) GC merupakan salah satu platform populer pada masa pandemi Covid-19. Cara untuk mengakses platform GC ini cukup dengan menggunakan akun g-mail (Iftakhar, 2016).

Model perkuliahan dengan mengintegrasikan WaG dan GC ini dapat membuat mahasiswa paham dengan materi perkuliahan. Hal ini dikarenakan materi perkuliahan disajikan dalam bentuk penjelasan video, handout, dan poster kemudian di posting pada kelas GC. Materi yang di posting tersebut tidak akan di hapus agar mahasiswa dapat melihat dan membaca secara berulang kali. Seperti yang dikemukakan oleh Izenstark dan Leahy (2015) bahwa platform GC 




dapat digunakan untuk memposting berbagai jenis dokumen, video, dan tautan, sehingga mempermudah peserta didik untuk mempelajari materi yang bersangkutan.

Selanjutnya, media pembelajaran juga harus mempertimbangkan biaya untuk mengaksesnya. Media WaG dan GC yang telah dirancang ini memiliki biaya yang relatif murah, sehingga hal ini menjadi salah satu alternatif mahasiswa untuk dapat terus mengikuti perkuliahan. Hal ini sejalan dengan Apriyanto dan Farhan (2021) bahwa media pembelajaran WhatsApp dan Google Classroom memiliki akses yang tidak mahal, sehingga masih dapat digunakan sebagai alternatif pembelajaran daring.

Unsur media pembelajaran selanjutnya yaitu adanya teknologi yang mendukung, hal ini menurut Susilana dan Riyana (2009) bahwa pembuatan media harus mempehatikan kondisi teknis agar media tersebut dapat digunakan dengan efektif dan efisien. Aplikasi WaG dan platform GC ini dapat dioperasikan dengan menggunakan handphone, laptop, atau tablet (Rahaded, Puspitasari, \& Hidayati, 2020; Singh, et al., 2020). Hal ini juga terlihat dari hasil penelitian yang menunjukkan bahwa mayoritas mahasiswa menggunakan handphone dan laptop untuk mengakses media WaG dan GC. Jadi teknologi yang digunakan oleh mahasiswa (handphone dan laptop) tersebut dapat digunakan untuk mengakses WaG dan GC dengan mudah.

Media pembelajaran yang dirancang untuk pembelajaran daring juga mampu memfasilitasi peserta didik untuk dapat berkomunikasi dengan peserta didik lain dan/atau pengajar (Susilana \& Riyana, 2009). Hasil tanggapan mahasiswa pada penelitian ini menunjukkan bahwa media WaG dan GC dapat membuat mereka berkomunikasi dengan dosen dan/atau mahasiswa lain ketika proses pembelajaran berlangsung melalui kegiatan diskusi. Aplikasi WaG merupakan salah satu sosial media. Menurut Barus dan Simanjutak (2020) sosial media dapat digunakan sebagai saluran komunikasi antar orang di seluruh dunia. Selain itu, GC juga dapat digunakan berkomunikasi ketika proses pembelajaran (Maras, 2021). Komunikasi GC dilakukan pada kolom komentar sesuai topik materi yang sudah di upload dengan cara menandai $e$-mail peserta didik.

Media yang diterapkan dalam proses pembelajaran ini memiliki keterbaruan. Hal ini ditunjukkan dengan mengintegrasikan WaG dengan GC, dimana pembukaan, konfirmasi, dan penutupan proses pembelajaran dilakukan melalui WaG. Selanjutnya untuk materi, absen, tugas, UTS, dan UAS di upload melalui GC. Hal ini dilakukan untuk melengkapi kekurangan dari masing-masing WaG dan GC. Menurut Cetinkaya (2017) WaG memiliki sisi ketidakefektifan seperti kadangkala ada pesan masuk dari grup lain atau orang lain, hal ini dapat mengganggu konsentrasi peserta didik. Selain itu banyak dari peserta didik yang mengirim pesan di grup tidak sesuai dengan topik pelajaran dan hal tersebut di kirim diluar jam pelajaran. Lebih lanjut Baishya \& Maheshwari (2020) untuk menghindari pesan yang tidak sesuai dengan topik, anggota grup dapat mematikan pemberitahuan suara/mute akan tetapi mereka dapat ketinggalan informasi yang disampaikan pengajar.

Selanjutnya kekurangan dari $\mathrm{WaG}$ tersebut ditunjang dengan platform GC. Hal ini dikarenakan platform tersebut mampu menyimpan konten materi dalam berbagai jenis dokumen, video, dan tautan (Izenstark \& Leahy, 2015). Apabila teknologi untuk mengakses platform GC ini sedang error, hilang, atau rusak, maka konten materi tersebut masih dapat diakses dengan teknologi lain. Peserta didik cukup melakukan login menggunakan akun g-mail yang sudah didaftarkan untuk mengakses platform GC tersebut.

\section{PENUTUP}

Penelitian ini menghasilkan rancangan model perkuliahan daring dengan mengintegrasikan WaG dan GC, dimana model ini dilakukan dengan tahap; (1) merancang media WaG dan GC; (2) mengisi materi perkuliahan pada media pembelajaran; (3) mengimplementasikan media pembelajaran pada kegiatan perkuliahan; (4) melakukan evaluasi terhadap model perkuliahan daring. Selanjutnya hasil evaluasi model perkuliahan daring dari 
tanggapan mahasiswa menunjukkan bahwa sebesar 54\% sangat setuju bahwa media WaG dan GC memiliki akses yang mudah, materi yang disampaikan mudah dipahami, biaya terjangkau, diskusi dapat dilakukan dengan lancar, dapat diakses dengan menggunakan teknologi handphone dan laptop, serta memiliki keterbaruan. Jadi media WaG dan GC tersebut efektif digunakan dalam proses pembelajaran.

Penelitian ini masih memiliki beberapa kekurangan, seperti; (1) proses pembelajaran masih menggunakan dua media yang berbeda, sehingga proses komunikasi masih membingungkan; (2) rekapitulasi nilai dan absen masih dilakukan melalui file yang berbeda yaitu menggunakan excel. Berdasarkan kekurangan tersebut diharapkan peneliti selanjutnya dapat melakukan proses pembelajaran dengan menggunakan satu media online yang sudah terintegrasi secara keseluruhan (pembukaan, penutup, absen, materi, tugas, UTS, UAS, rekapitulasi administrasi), sehingga proses pembelajaran dapat dipandu dan dipantau satu arah saja.

\section{DAFTAR PUSTAKA}

Ahmed, M. M., \& Indurkhya, B. (2020). Investigating Cognitive Holding Power and Equity in The Flipped Classroom. Heliyon, 6, 1-9. doi:https://doi.org/10.1016/j.heliyon.2020.e04672

Albashtawi, A. H., \& Al Batainch, K. B. (2020). The Effectiveness of Google Classroom Among EFL Students in Jordan: An Innovative Teaching and Learning Online Platform. International Journal of Emerging Technologies in Learning, 15(11), 78 - 88. doi:https://doi.org/10.3991/ijet.v15i11.12865

Apriyanto, M. T., \& Farhan, M. (2021). Merancang Pembelajaran Matematika Daring Sederhana dengan Aplikasi Whatsapp Kombinasi Google Classroom Pada Masa Pandemi. Prosiding Seminar Nasional Penelitian dan Pengabdian 2021. 1, hal. 115 - 128. Tasikmalaya: Rumah Cemerlang Indonesia (RCI). Diambil kembali dari http://prosiding.rcipublisher.org/index.php/prosiding/issue/view/1

Baishya, D., \& Maheshwari, S. (2020). Whatsapp Groups in Academic Context: Exploring the Academic Uses of Whatsapp Group among the Students. Contemporary Educational Technology, 11(1), 31 - 46. doi:https://doi.org/10.30935/cet.641765

Barus , I. R., \& Simanjutak, M. B. (2020). Whatsapp Group and Google Classroom-Based Learning Materials in English Classes: Students' Perception (Study Case Taken from College of Vocational Studies - IPB University). Scope of English Language Teaching, Literature and Linguistics, 3(1), 47 - 54. Diambil kembali dari https://ejournals.umma.ac.id/index.php/seltics

Cetinkaya, L. (2017). The Impact of Whatsapp Use on Success in Education Process. International Review of Research in Open and Distributed Learning , 18(7), 58 - 74. doi:https://doi.org/10.19173/irrodl.v18i7.3279

Hanisi, A. L., Risdiany, R., Utami, Y. D., \& Sulisworo, D. (2018). The use of WhatsApp in Collaborative Learning to Improve English Teaching and Learning Process. International Journal of Research Studies in Educational Technology, 7(1), 29-35. doi:https://doi.org/10.5861/ijrset.2018.3004

Iftakhar, S. (2016). Google Classroom: What Works and How ? Journal of Education and Social Sciences, 3(1), 12 - 18. Diambil kembali dari https://www.jesoc.com/issue/volume-3-february2016/

Izenstark, A., \& Leahy, K. L. (2015). Google Classroom for Librarians: Features and Opportunities. Library Hi Tech News, 32(9), 1 - 3. doi: https://doi.org/10.1108/LHTN-05-2015-0039 




Keller, A., \& Miller, L. (2015). 50 Things You can do with Google Classroom. San Diego: Dave Burgess Consulting, Inc.

Maras, A. (2021). Teacher - Student Communication from Parents' Perspective During Online Teaching in the Time of Corona Crisis. Proceedings of the International Scientific Conference . 5, hal. 158 - 169. Rezekne, Latvia: Rezeknes Tehnologiju Akademija. doi: https://doi.org/10.17770/sie2021vol5.6217

Mishra, L., Gupta, T., \& Shree, A. (2020). Online Teaching-Learning in Higher Education During Lockdown Period of Covid-19 Pandemic. International Journal of Educational Research Open, 1, 1-8. doi:https://doi.org/10.1016/j.ijedro.2020.100012

Novelino, A. (2020, November 20). Peristiwa Nasional. Diambil kembali dari CNN Indonesia: https://www.cnnindonesia.com/nasional/20201120125838-20-572335/nadiem-izinkan-pemdabuka-sekolah-di-semua-zona-januari-2021

Oriji, A., \& Anikpo, F. (2019). Social Media in Teaching-Learning Process: Investigation of the Use of Whatsapp in Teaching and Learning in University of Port Harcourt. European Scientific Journal, 15(4), 15 - 39. doi:http://dx.doi.org/10.19044/esj.2019.v15n4p15

Rahaded, U., Puspitasari, E., \& Hidayati, D. (2020). The Impact of Whatsapp Toward UAD Undergraduate Students' Behavior in Learning Process. International Journal on Education, Management and Innovation (IJEMI) , $1(1), \quad 55$ - 68. doi:https://doi.org/10.12928/ijemi.v1i1.1515

Singh, C. K., Singh, T. S., Abdullah, N. Y., Moneyam, S., Ismail, M. R., Ong, E., . . Singh, J. K. (2020). Rethinking English Language Teaching Through Telegram, Whatsapp, Google Classroom, and Zoom. Systematic Reviews in Pharmacy, 11(11), 45 - 54. doi:https://doi.org/10.31838/srp.2020.11.9

Susilana, R., \& Riyana, C. (2009). Media Pembelajaran: Hakikat, Pengembangan, Pemanfaatan, dan Penilaian. Bandung: CV Wacana Prima. 